\title{
Evolving
}

\section{Totally endoscopic coronary artery bypass grafting on cardiopulmonary bypass with robotically enhanced telemanipulation: Report of forty-five cases}

\author{
S. Dogan, $M D^{a}$ \\ T. Aybek, MD ${ }^{\mathrm{a}}$ \\ E. Andre $\beta e n, M^{a}$ \\ C. Byhahn, $M^{\mathrm{a}}$ \\ S. Mierdl, $M D^{\mathrm{b}}$ \\ K. Westphal, MD, PhD \\ G. Matheis, MD \\ A. Moritz, MD, PhD \\ G. Wimmer-Greinecker, MD, $\mathrm{PhD}^{\mathrm{a}}$
}

See related editorial on page 1029.

\footnotetext{
From the Department of Thoracic and Cardiovascular Surgery ${ }^{\mathrm{a}}$ and the Department of Anesthesiology, Intensive Care and Pain

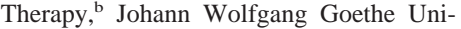
versity, Frankfurt, Germany.

Received for publication March 27, 2001; revisions requested May 17, 2001; revisions received Oct 9, 2001; accepted for publication Oct 24, 2001.

Address for reprints: Selami Dogan, MD, Department of Thoracic and Cardiovascular Surgery, Johann Wolfgang Goethe University Frankfurt, Theodor Stern Kai 7, 60590 Frankfurt, Germany (E-mail: S.Dogan@em.uni-frankfurt.de).

J Thorac Cardiovasc Surg 2002;123: 1125-31

Copyright $\odot 2002$ by The American Association for Thoracic Surgery

0022-5223/2002 \$35.00+0 $\quad \mathbf{1 2 / 1 / 1 2 1 3 0 5}$ doi:10.1067/mtc.2002.121305
}

Background: Robotically enhanced telemanipulation is a new powerful tool for minimally invasive procedures that allows totally endoscopic cardiac surgery. Between June 1999 and February 2001, 45 robotically enhanced totally endoscopic coronary artery bypass grafting procedures on the arrested heart were performed at our institution with the use of the da Vinci telemanipulation system (Intuitive Surgical, Inc, Mountain View, Calif).

Methods: In 37 patients a single-vessel totally endoscopic coronary bypass operation was performed. Eight patients had different types of multivessel revascularization with both internal thoracic arteries. The initial conversion rate was $22 \%$ and dropped to $5 \%$ in the last 20 patients. Two patients required reexploration via median sternotomy. The first 22 patients had excellent graft patency on discharge. The procedural time for single-vessel totally endoscopic bypass was $4.2 \pm 0.4$ hours, bypass time was $136 \pm 11$ minutes, and aortic crossclamp time amounted to $61 \pm 5$ minutes.

Conclusion: The present data show the feasibility of closed chest single- and double-vessel revascularization, with good clinical results. However, procedural time is prolonged and the complex endoscopic and endoaortic occlusion techniques, as well as the extensive anesthesiologic monitoring, are demanding. The need for conversion to an open procedure diminished after a relatively short learning curve. All postulated benefits of totally endoscopic surgery other than excellent cosmesis must be evaluated in larger cohorts.

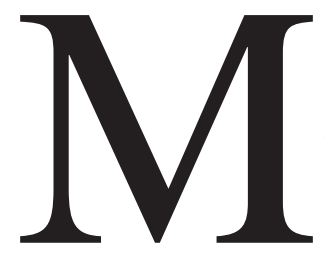

inimally invasive cardiac surgery follows two basic concepts: First, operations without cardiopulmonary bypass (CPB) strive to reduce inflammatory whole body response and emboli. The second philosophy aims to minimize incisions and surgical trauma. ${ }^{1}$ Several techniques were developed to achieve coronary artery bypass grafting via an anterolateral minithoracotomy. ${ }^{2-6}$ The minimally invasive direct coronary artery bypass (MID- 


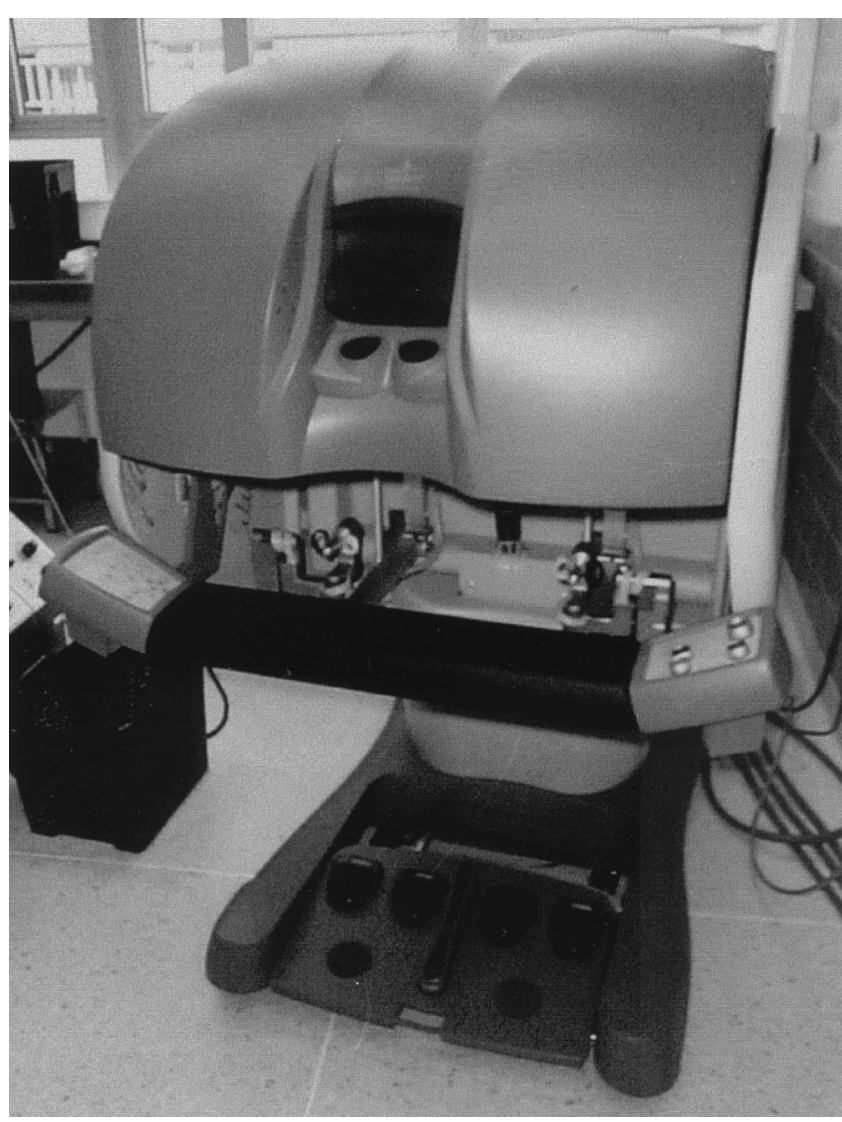

Figure 1. The da Vinci surgical console (control unit).

$\mathrm{CAB}$ ) technique combines the advantages of limited surgical access with the benefits of off-pump surgery, but it is limited to revascularization of a maximum of 2 target vessels. For complete multivessel revascularization with limited incisions, CPB still depends on new but less biocompatible technologies such as the Port-Access system (Heartport, Inc, Redwood City, Calif). ${ }^{7-10}$

With the advent of robotically enhanced telemanipulation, a new powerful tool has been created to further minimize surgical access, thus allowing true closed chest totally endoscopic procedures. ${ }^{11-14}$ Our university initiated a clinical program using the da Vinci surgical system (Intuitive Surgical, Inc, Mountain View, Calif) for all surgical disciplines in June 1999. This article outlines our clinical experience with closed chest cardiac surgery in 45 totally endoscopic coronary artery bypass (TECAB) procedures using this robotic telemanipulation device.

\section{Patients and Methods}

After we had undertaken cadaver training, the initial 7 patients of the cardiac arm of the program underwent only parts of the procedure with the telemanipulator for safety reasons (either internal thoracic artery [ITA] dissection or grafting of the left anterior descending coronary artery [LAD]). All following consecutive
TABLE 1. Totally endoscopic procedures

\begin{tabular}{lc}
\hline Procedure & No. of patients \\
\hline LITA-LAD & 33 \\
RITA-RCA & 4 \\
LITA-DB-LAD & 5 \\
LITA-LAD-RITA-RCA & 2 \\
RITA-LAD-LITA-RCX & 1
\end{tabular}

$\overline{L I T A \text {, Left internal thoracic artery; } L A D \text {, left anterior descending coronary }}$ artery; $R I T A$, right internal thoracic artery; $D B$, diagonal branch; $R C A$, right coronary artery; $R C X$, right circumflex.

single-vessel operations were performed as complete closed chest procedures. This article refers to the latter 45 patients, who underwent the TECAB procedure.

Institutional ethical committee approval was obtained, and each patient gave written informed consent. The 45 patients (32 male, 13 female) were $63 \pm 6$ years old. The procedures are listed in Table 1. Left ventricular ejection fraction was $56 \% \pm 5 \%$, and New York Heart Association functional class was $2.1 \pm 0.2$. Twenty-four patients had a history of smoking and 12 had diabetes. Patients with significant comorbidity, including reduced pulmonary function and ascending aortic and peripheral vascular disease, did not fit the inclusion criteria for the Port-Access procedure and therefore were not considered for closed chest surgery.

\section{Anesthesia for TECAB}

After standard induction of anesthesia, patients underwent doublelumen intubation for single lung ventilation. Both radial arteries were cannulated for invasive monitoring of the endoaortic occlusion catheter. A transesophageal echo probe was routinely inserted to assess cardiac function and to place and monitor the Port-Access system. In addition, a pulmonary artery vent catheter was inserted percutaneously through the right jugular vein.

\section{The da Vinci Surgical System}

The da Vinci telemanipulation system consists of a master console (Figure 1) for remote control of the microinstruments mounted on a surgical cart with three arms (slave unit, Figure 2). The middle arm carries a stereo endoscope, and the left and right arms serve as endothoracic end effectors for remote tissue manipulation using microinstruments resembling the human wrist. An additional video cart carries the light source, a carbon dioxide insufflator, an image processor, and a conventional 2-dimensional screen. In our program a surgical resident places the ports and cannulates femoral vessels for CPB. The surgeon is seated at the master console and controls the endoscopic instruments, as well as the camera mounted on the slave unit. The video image from the stereo endoscope is transferred to the master console, magnified $(10 \times)$, and projected as a 3-dimensional image for optimal visualization of the surgical field.

\section{Operative Technique for TECAB}

Both ITAs can be approached from both the left and the right hemithoraces. In a typical left-sided approach for left ITA-LAD bypass, the patient is placed on the operating room table in a supine position with the left side of the chest elevated about $30^{\circ}$ to 
$40^{\circ}$. The thoracic landmarks such as jugulum, xiphoid, and ribs are marked for external orientation and port placement. After deflation of the left lung, the camera port is placed bluntly to avoid left ventricular injury. Usually the fifth intercostal space close to the anterior axillary line is identified and the chest is insufflated with warm carbon dioxide $\left(37^{\circ} \mathrm{C}\right)$. After insertion of the endoscope, two ports are placed under visual control to accommodate the two robot arms, usually in the third and seventh intercostal spaces. The left ITA is mobilized from the subclavian artery all the way down to the distal bifurcation with a $30^{\circ}$ endoscope angled upward. Most side branches of the ITA are cauterized by means of low-energy cautery. The distal end of the ITA and one additional segment are skeletonized for grafting, and a soft bulldog clamp (Scanlan Int, St Paul, Minn) is placed.

The left femoral artery and vein are dissected by means of a $3-\mathrm{cm}$ oblique incision in the groin. After heparinization, CPB is instituted by femoro-femoral bypass with the use of the PortAccess system. Alternatively we have used the Estech perfusion catheter (Estech Systems, Inc, Plano, Tex), which provides antegrade aortic flow with femoral cannulation. After initiation of CPB and venting of the right ventricle via the pulmonary artery vent, the heart is decompressed and endoscopic pericardiotomy can be performed safely. Identification of the target vessel is crucial and should be performed before cardiac arrest. Infusion of antegrade crystalloid St Thomas' Hospital cardioplegic solution into the aortic root via the Port-Access EndoClamp device provides reliable cardiac arrest. In patients with mild aortic regurgitation, we routinely insert a coronary sinus cardioplegia catheter. Procedures in this initial cohort have been performed with moderate systemic hypothermia $\left(25^{\circ} \mathrm{C}-28^{\circ} \mathrm{C}\right)$ for safety reasons.

In patients with left ITA-LAD grafting a 6- to 7-mm arteriotomy is carried out, and the left ITA is grafted end to side with a running 7-0 Prolene suture (7.5-cm length, Fumalene; Fumedica Medizintechnik, Herne, Germany). In 5 patients a sequential bypass to the LAD and the first diagonal branch was performed. First, the end-to-side anastomosis to the LAD was completed and then the ITA graft was anastomosed side to side to the first diagonal branch by using the same suture. Bilateral ITA takedown was performed from the left side for LAD and circumflex artery grafting in 1 case. For bilateral ITA grafting of the LAD and right coronary artery (RCA), a right-sided approach was used following exactly the same guidelines. During ITA harvesting and performance of the anastomosis, the carbon dioxide pressure is kept at 10 to $14 \mathrm{~mm} \mathrm{Hg}$ depending on the space needed in the chest cavity and hemodynamic status.

After completion of the anastomosis the endoaortic occlusion catheter is deflated and the patient is weaned from CPB. Venous and arterial cannulas are removed, and the defect in the femoral vein is secured by a purse-string suture, while the femoral artery incision is closed with a running suture. Two chest tubes are placed through the camera port and an instrument port incision.

\section{Results}

Fifty-two patients underwent cardiac surgery with robotically enhanced telemanipulation at Johann Wolfgang Goethe University. The first 7 patients of this series either underwent endoscopic left ITA mobilization or a robotic coronary artery bypass anastomosis as part of an otherwise

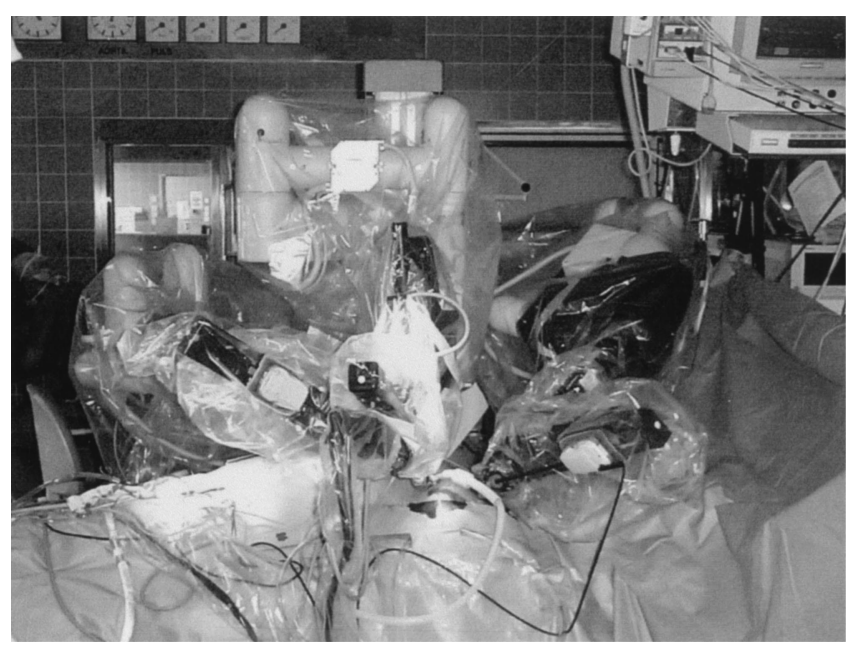

Figure 2. The da Vinci surgical cart (slave unit).

TABLE 2. Morbidity and complications

\begin{tabular}{lcc}
\hline & No. & $\%$ \\
\hline Conversion to minithoracotomy & 7 & 15.6 \\
Conversion to full sternotomy & 3 & 6.7 \\
Bleeding from the anastomosis & 2 & 4.4 \\
Prolonged crossclamp time & 4 & 8.9 \\
ITA injury & 1 & 2.2 \\
Port-Access failure & 3 & 6.7 \\
Hypovolemic shock & 1 & 2.2 \\
Myocardial infarction & 1 & 2.2 \\
Hypoxic brain damage & 1 & 2.2 \\
Moderate reperfusion injury & 1 & 2.2 \\
Retrograde aortic dissection & 1 & 2.2 \\
\hline
\end{tabular}

ITA, Internal thoracic artery.

conventional $\mathrm{CABG}$ procedure. After this initial series, 45 consecutive patients with single- or double-vessel coronary artery disease were operated on without opening the chest. Table 1 shows the operations performed at our institution. In most cases a single arterial bypass with either the left ITA to LAD or right ITA to RCA was performed $(n=37)$. In 8 patients more complex double-vessel bypass procedures were carried out. Of the initial 20 coronary cases that were started with a closed chest approach intention, 10 patients $(22 \%)$ required a controlled intraoperative conversion to either left-sided minithoracotomy $(n=7)$ or median sternotomy $(\mathrm{n}=3)$. Four of these 10 conversions occurred in double bypass surgery. The reasons for conversion were intraoperative bleeding from the anastomotic site $(n=2)$, prolonged crossclamp time beyond 2 hours $(n=4)$, injury to the ITA graft $(n=1)$, and contraindication to advance the Port-Access EndoClamp device $(\mathrm{n}=3)$ after intraoperative diagnosis of severe previously undiagnosed peripheral artery disease. In the last 20 patients of the series only 1 conversion to minithoracotomy $(5 \%)$ was necessary. The 
TABLE 3. Intraoperative data of totally endoscopic procedures

\begin{tabular}{lcccccc}
\hline Patient groups & $\begin{array}{c}\text { Operating } \\
\text { time }(\mathbf{h})\end{array}$ & $\begin{array}{c}\text { Port placement } \\
(\mathbf{m i n})\end{array}$ & $\begin{array}{c}\text { ITA takedown } \\
(\mathbf{m i n})\end{array}$ & $\begin{array}{c}\text { Anastomosis } \\
(\mathbf{m i n})\end{array}$ & $\begin{array}{c}\text { CPB time } \\
(\mathbf{m i n})\end{array}$ & $\begin{array}{c}\text { Crossclamp time } \\
(\mathbf{m i n})\end{array}$ \\
\hline $\begin{array}{c}\text { Single vessel }(\mathrm{n}=37) \\
\text { (LITA-LAD, RITA-RCA) }\end{array}$ & $4.2 \pm 0.9$ & $15.4 \pm 5.7$ & $65 \pm 21$ & $18.4 \pm 3.8$ & $136 \pm 32$ & $61 \pm 16$ \\
$\begin{array}{c}\text { Double vessel }(\mathrm{n}=8) \\
\text { (LITA-DB-LAD, BITA) }\end{array}$ & $6.3 \pm 1.0$ & $18.4 \pm 4.9$ & $118 \pm 12.3$ & $21.1 \pm 6.3$ & $197 \pm 63$ & $99 \pm 55$ \\
\hline
\end{tabular}

Values are mean $\pm S D$. LITA, Left internal thoracic artery; $L A D$, left anterior descending coronary artery; RITA, right internal thoracic artery; $R C A$, right coronary artery; $D B$, diagonal branch; $B I T A$, bilateral internal thoracic arteries.

TABLE 4. Postoperative data of totally endoscopic procedures

\begin{tabular}{|c|c|c|c|c|c|c|}
\hline Patient groups & $\begin{array}{c}\text { CK (U/L, } 6 \text { h } \\
\text { postop) }\end{array}$ & $\begin{array}{c}\text { CK-MB, } \\
\text { n = } 31 \text { (U/L, } \\
6 \text { h postop) }\end{array}$ & $\begin{array}{l}\text { Postop } \\
\text { bleeding } \\
\text { (mL) }\end{array}$ & Ventilation (h) & ICU stay (h) & Hospital stay (d) \\
\hline $\begin{array}{l}\text { Single vessel }(n=37) \\
\quad(\text { LITA-LAD, RITA-RCA) }\end{array}$ & $\begin{array}{r}586 \pm 514 \\
(\mathrm{n}=31)\end{array}$ & $\begin{aligned} 14.2 & \pm 10.9 \\
(\mathrm{n} & =31)\end{aligned}$ & $\begin{array}{r}743 \pm 671 \\
(\mathrm{n}=37)\end{array}$ & $\begin{array}{l}18 \pm 15 \\
(\mathrm{n}=37)\end{array}$ & $\begin{array}{l}24 \pm 21 \\
(\mathrm{n}=37)\end{array}$ & $\begin{array}{l}8.6 \pm 2.7 \\
(n=37)\end{array}$ \\
\hline Double vessel $(n=8)$ & $1797 \pm 1884$ & $18.2 \pm 13.1$ & $968 \pm 821$ & $41.1 \pm 28$ & $74 \pm 64$ & $15.4 \pm 6.4$ \\
\hline
\end{tabular}

(LITA-DB-LAD, BITA)

Values are mean $\pm S D$. LITA, Left internal thoracic artery; $L A D$, left anterior descending coronary artery; RITA, right internal thoracic artery; $D B$, diagonal branch; BITA, bilateral internal thoracic artery.

overall morbidity and complications are summarized in Table 2.

Mean operative time for single-vessel TECAB was markedly prolonged compared with MIDCAB or standard surgery. The time for port placement, ITA dissection, endoscopic anastomosis, and duration of $\mathrm{CPB}$ and crossclamping are summarized in Table 3. Table 4 demonstrates postoperative data.

The first 22 patients undergoing TECAB had angiograms before discharge from the hospital (Figures 3 and 4), showing patent grafts in all cases. Only 1 ITA graft displayed a nonsignificant stenosis in the middle segment. The cosmetic result of a closed chest bypass procedure is shown in Figure 5.

Perioperative complications comprised 1 case of intraoperative exploration via a median sternotomy because of hemodynamic compromise at the end of a long procedure with anastomosis of the right ITA to the LAD and anastomosis of the left ITA to the marginal branch of the circumflex artery. After exploration via median sternotomy, the only cause for hemodynamic instability was found to be extreme hypovolemia. One patient had hypoxic brain damage after a complicated resuscitation after pericardial tamponade. Two patients required postoperative reexploration because of bleeding from the anastomotic site (1 of whom underwent double bypass). One patient had moderate reperfusion injury of the cannulated leg on decannulation and 1 patient with a left ITA bypass to the LAD had a postoperative myocardial infarction because of vasospasm of the RCA requiring angioplasty and stent implantation. One patient with closed chest bilateral ITA grafting to the LAD and the RCA had postoperative retrograde aortic dissection after puncture of the cannulated groin for a follow-up angiogram. There was no wound infection at the port site in this series. We observed 1 superficial wound infection and 1 hematoma in the groin after femoral cannulation.

\section{Discussion}

The surgical treatment of single-vessel coronary artery disease is primarily dominated by established techniques such as MIDCAB or off-pump coronary artery bypass (OPCAB) in many centers. TECAB, however, is an evolving method, which is intended to further minimize surgical trauma and pain, reduce the risk of wound infection, and preserve a stable chest cavity. This series reflects 45 patients for whom our "intention to treat" was the closed chest technique. The threshold to convert a patient to an open technique was set rather low to minimize the risk for the patient. Ten patients had intraoperative conversion to either minithoracotomy or median sternotomy. In 4 of these 10 patients a double bypass revascularization, that is, a more complex procedure, was attempted. In 4 patients of this early cohort we decided to convert to either left-sided minithoracotomy or median sternotomy because a crossclamp time beyond 2 hours was not acceptable to us. In 2 patients we observed leakage from the anastomosis that we could not control by endoscopic techniques. This was mainly due to a lack of countertraction to tighten the posterior running suture line. Interrupted suture clips may be appropriate in this scenario but have not been studied so far in this cohort. Three patients were 


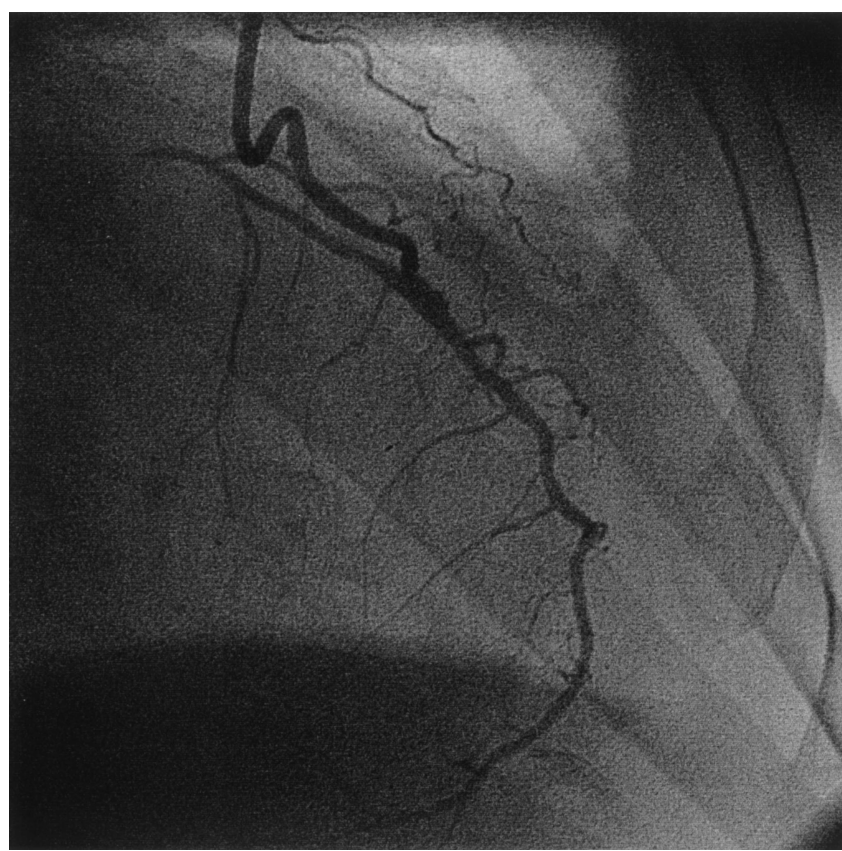

Figure 3. TECAB follow-up angiogram, left ITA to LAD.

converted to minithoracotomy because of problems associated with Port-Access surgery. ${ }^{8,9}$ The conversion rate may have been lower if we had a perfect endoscopic cannulation system. Using Port-Access technology in totally endoscopic surgery, we are dealing not only with a novel complex robotically enhanced endoscopic technique but also with the difficulties of endoscopic cannulation and endoaortic occlusion.

The complications cited above exceed those reported for single coronary artery bypass (MIDCAB ${ }^{6,15}$ ) and do not reflect a safety standard that would make TECAB an operation suitable for routine use. However, it is important to note that the majority of complications occurred in the first 20 patients of this series and are clearly attributable to the learning curve. After successful management of this initial learning curve, looking at the recent cohort of 25 consecutive patients, single-vessel TECAB became a straightforward procedure with a low conversion and complication rate and acceptable operating time at our institution.

Adequate port placement was possible in all patients, including an extremely obese woman with large breasts, allowing sufficient endothoracic movement of the instruments. We believe that especially these patients benefit from an endoscopic procedure, because the risk of wound infection is minimized. The feasibility and safety of closed chest ITA takedown has been shown by several other groups. ${ }^{16,17}$

A sequential arterial bypass with the left ITA to the first diagonal branch and the LAD was performed successfully with excellent functional results but a slightly longer operating time. ${ }^{18}$ A sequential revascularization of the first di-

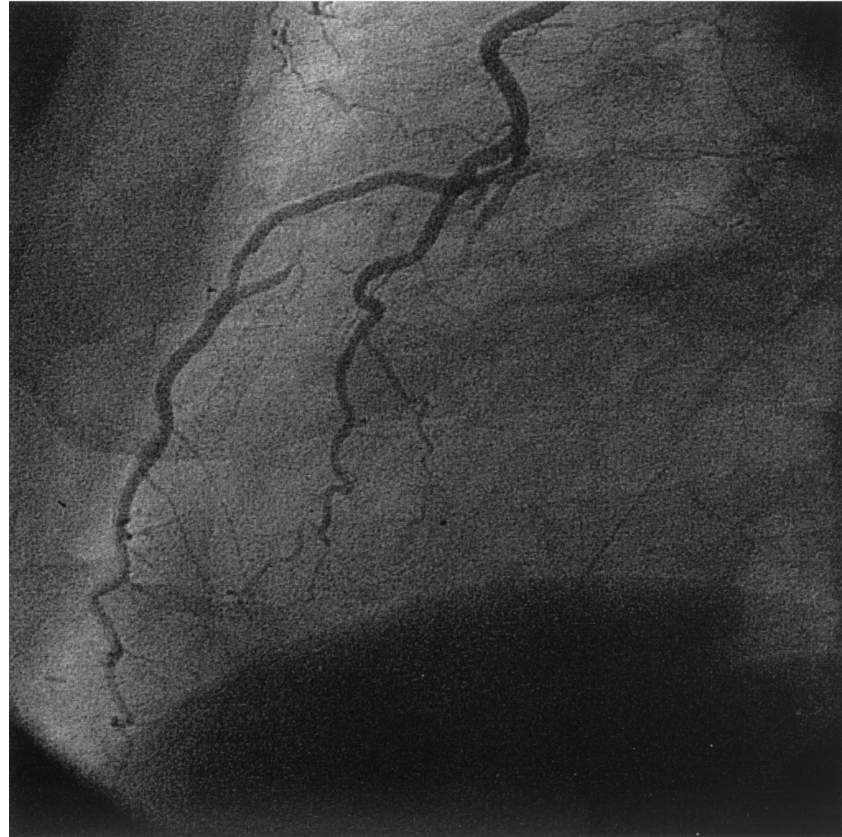

Figure 4. Sequential TECAB follow-up angiogram, left ITA-diagonal branch-LAD.

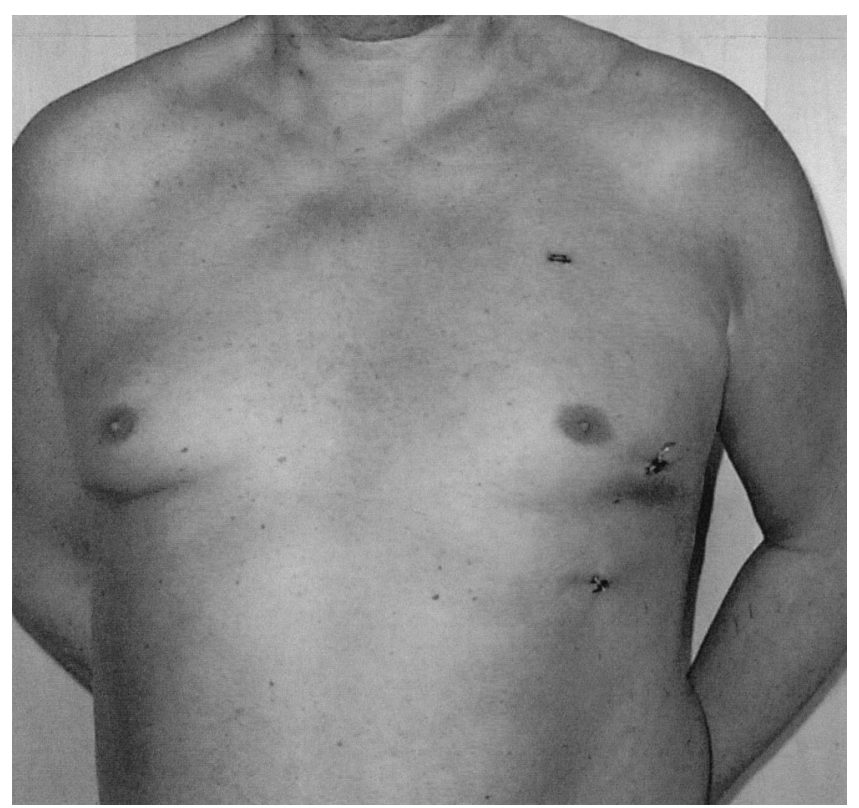

Figure 5. Early postoperative result after TECAB.

agonal branch and the LAD can be somewhat cumbersome via a MIDCAB approach because of bad accessibility of the diagonal branch for side-to-side anastomosis. We believe that the endoscopic technique is a viable alternative in cases in which it is desirable to avoid median sternotomy.

Bilateral ITA grafting is feasible but appears to be very challenging and time consuming. Such a procedure should be accepted only for very special indications. One 36-year- 
old obese female patient with type I diabetes for 16 years was revascularized successfully with 2 ITA grafts by means of the TECAB technique. Such a constellation justifies a long and complex procedure since the risk of mediastinitis is increased in such patients. ${ }^{19,20}$

Technically, the identification of the target coronary vessel can be difficult in patients with an intramural course, and additional preoperative assessment may be useful. We used multidetector computed tomographic scanning to determine the exact position of the coronary target site and vessel quality. Thus, we were able to revascularize 5 patients with intramural LAD successfully with the TECAB technique.

The analysis of postoperative cardiac enzyme levels was unremarkable, and the incidence of perioperative myocardial infarction was $2 \%$. The only postoperative myocardial infarction was not associated with the particular technique and occurred in the RCA region of a patient with left ITA-LAD grafting. This patient had spasm of the RCA postoperatively and required angioplasty and stent implantation. The early angiographic results were excellent in the first 22 patients undergoing TECAB, prompting us to stop performing postoperative angiograms to improve patient comfort and overall cost. There was no chest wound infection at the port site, and only one patient had a superficial groin infection. One patient showed a moderate reperfusion syndrome of a cannulated leg, which was the only such complication observed in 140 institutional Port-Access cases. The postoperative course, including chest tube drainage, mechanical ventilation time, and intensive care unit and hospital stay, was within the limits of our institutional patient cohort receiving coronary revascularization. However, there was no intention to shorten hospital stay below 7 days because of German reimbursement issues.

The da Vinci surgical system changes interaction between operating room team members. The surgeon at the console, the table-side surgeon, the perfusionist, and the anesthesiologist need excellent team working and communication skills. Because every single step of the procedure must be anticipated by the assistant to allow the efficient exchange of instruments, the course of the procedure depends on a close communication of team members with a great amount of patience and discipline. Since the surgeon immerses into the operative field completely via the 3-dimensional visualization system, the assistant has to be responsible for adequate patient condition. All these factors contribute to extended procedural time as compared with MIDCAB or other types of standard operations.

The hemodynamic and anesthesiologic management of patients undergoing TECAB poses a new challenge to cardiac anesthesia. ${ }^{16}$ Carbon dioxide insufflation increases intrathoracic pressure, which may impair cardiovascular function, especially when the intracardiac volume load is not controlled properly. We examined hemodynamics and gas exchange during carbon dioxide insufflation into the closed chest. There was no adverse effect on hemodynamics and gas exchange during single lung ventilation. However, markedly elevated arterial carbon dioxide tensions were observed during bilateral insufflation, which sometimes occurs in bilateral ITA takedown. ${ }^{17}$ In the absence of direct visualization of cardiac filling status and extended operating times with considerable perspiration and fluid shifts, adequate fluid therapy is critical in closed chest cases and requires online echocardiographic assessment. In the present series, 1 patient was in hypovolemic shock at the end of the operation; the patient's condition became evident only after surgical reexploration.

Despite attempts to perform totally endoscopic surgery with the da Vinci system on the beating heart, the success rate of such procedures remains low. ${ }^{21,22}$ Our preliminary experience with 3 cases of totally endoscopic off-pump surgery (TOPS) identifies several critical issues such as stabilization of the coronary artery in the limited intrathoracic space. In TOPS these drawbacks will add up to the specific problems of TECAB described above. However, avoidance of CPB via the Port-Access system may shorten operating time in the future. Direct comparison with the MIDCAB technique will be possible only when TOPS becomes a reproducible and safe operation.

Some advantages of the totally endoscopic technique are obvious, such as reduction of wound infections, preservation of a stable thorax, and the excellent cosmetic result. As in other technology-based surgical innovations such as endoscopic cholecystectomy in the early 1990s, the learning curve is acceptable and the performance of this procedure may improve, especially with further technical development of the robotic system. We assume that the addition of refined endoscopic stabilizers will facilitate TOPS and thereby remove the need for complex endoscopic cannulation systems and shorten operating times. Regarding cost, robotically enhanced surgery is obviously more expensive than other treatment alternatives. Whether the benefits of the procedure will one day justify the increased cost remains unknown.

\section{References}

1. Kirklin JK, Westaby S, Blackstone EH, Kirklin JW, Chenoweth DE, Pacifico AD. Complement and the damaging effects of cardiopulmonary bypass. J Thorac Cardiovasc Surg. 1983;86:845-57.

2. Talwalkar NG, Cooley DA. Minimally invasive coronary artery bypass grafting: a review. Cardiol Rev. 1998;6:345-9.

3. Duhaylongsod FG. Minimally invasive cardiac surgery defined. Arch Surg. 2000;135:296-301. Review.

4. Vassiliades TA Jr, Rogers EW, Nielsen JL, Lonquist JL. Minimally invasive direct coronary artery bypass grafting: intermediate-term results. Ann Thorac Surg. 2000;70:1063-5.

5. Diegeler A. Left internal mammary artery grafting to left anterior descending coronary artery by minimally invasive direct coronary artery bypass approach. Curr Cardiol Rep. 1999;1:323-30. 
6. Cremer JT, Wittwer T, Boning A, Anssar MB, Kofidis T, Mugge A, et al. Minimally invasive coronary artery revascularization on the beating heart. Ann Thorac Surg. 2000;69:1787-91.

7. Groh M, Grossi EA. Multivessel coronary bypass grafting with minimal access using cardiopulmonary bypass. Curr Cardiol Rep. 1999; $1: 331-4$.

8. Wimmer-Greinecker G, Matheis G, Dogan S, Aybek T, Mierdl S, Kessler P, et al. Patient selection for Port-Access multi vessel revascularization. Eur J Cardiothorac Surg. 1999;16(Suppl 2):S43-7.

9. Wimmer-Greinecker G, Matheis G, Dogan S, Aybek T, Kessler P, Westphal K, et al. Complications of port-access cardiac surgery. J Card Surg. 1999;14:240-5.

10. Glower DD, Komtebedde J, Clements FM, Debruijn NP, StaffordSmith M, Newman MF. Direct aortic cannulation for port-access mitral or coronary artery bypass grafting. Ann Thorac Surg. 1999;68: 1878-80.

11. Loulmet D, Carpentier A, d'Attellis N, Berrebi A, Cardon C, Ponzio $\mathrm{O}$, et al. Endoscopic coronary artery bypass grafting with the aid of robotic assisted instruments. J Thorac Cardiovasc Surg. 1999;118:410 .

12. Boehm DH, Reichenspurner H, Gulbins H, Detter C, Meiser B, Brenner P, et al. Early experience with robotic technology for coronary artery bypass surgery, Ann Thorac Surg. 1999;68:1542-6.

13. Falk V, Diegeler A, Walther T, Banusch J, Brucerius J, Raumans J, et al. Total endoscopic computer enhanced coronary artery bypass grafting. Eur J Cardiothorac Surg. 2000;17:38-45.

14. Kappert U, Schneider J, Cichon R, Gulielmos V, Matschke K, Tugtekin SM, et al. Wrist-enhanced instrumentation: moving toward totally endoscopic coronary artery bypass grafting. Ann Thorac Surg. 2000;70:1105-8

15. Diegeler A, Matin M, Falk V, Binner C, Walther T, Autschbach R, et al. Quality assessment in minimally invasive coronary artery bypass grafting. Eur J Cardiothorac Surg. 1999;16(Suppl 2):S67-72.

16. Kessler P, Mierdl S, Lischke V, Byhahn C, Aybek T, Dogan S, et al. Anesthetic considerations for robotics. Cardiovasc Eng. 2000; 5:261-6

17. Byhahn C, Mierdl S, Meininger D, Wimmer-Greinecker G, Matheis G, Westphal K. Hemodynamics and gas exchange during carbon dioxide insufflation for totally endoscopic coronary artery bypass grafting. Ann Thorac Surg. 2001;71:1496-501

18. Dogan S, Aybek T, Westphal K, Mierdl S, Moritz A, WimmerGreinecker G. Computer-enhanced totally endoscopic sequential arterial coronary artery bypass. Ann Thorac Surg. 2001;72:610-1.

19. Braxton JH, Marrin CA, McGrath PD, Ross CS, Morton JR, Norotsky $\mathrm{M}$, et al. Mediastinitis and long-term survival after coronary artery bypass surgery. Ann Thorac Surg. 2000;70:2004-7.

20. Borger MA, Rao V, Weisel RD, Ivanov J, Cohen G, Scully HE, et al Deep sternal wound infection: risk factors and outcomes. Ann Thorac Surg. 1998;65:1050-6.

21. Falk V, Diegeler A, Walther T, Jakobs S, Raumans J, Mohr FW. Total endoscopic off-pump coronary artery bypass grafting. Heart Surg Forum. 2000;3:29-31.

22. Mohr FW, Falk V, Diegeler A, Walther T, Gummert JF, Bucerius J, et al. Computer-enhanced "robotic" cardiac surgery: experience in 148 patients. J Thorac Cardiovasc Surg. 2001;121:842-53.

\section{Online-www.aats.org}

Now you can get The Journal of Thoracic and Cardiovascular Surgery online. The Journal online brings you faster delivery time, easy searching of current and back issues, links to PubMed, AATS, WTSA, and other important sites, and more. Visit the Journal online today.

\section{Receive tables of contents by e-mail}

To receive the tables of contents by e-mail, sign up through our Web site at http://www.mosby.com/jtcvs

Choose E-mail Notification

Simply type your e-mail address in the box and click the Subscribe button.

Alternatively, you may send an e-mail message to majordomo@mosby.com.

Leave the subject line blank and type the following as the body of your message: subscribe jtcvs_toc

You will receive an e-mail to confirm that you have been added to the mailing list.

Note that TOC e-mails will be sent out when a new issue is posted to the Web site. 